\title{
АНАЛИЗ ГОСУДАРСТВЕННОЙ ПОДДЕРЖКИ ИННОВАЦИОННОЙ ДЕЯТЕЛЬНОСТИ
}

\section{ANALYSIS OF STATE SUPPORT OF INNOVATIVE ACTIVITIES}

\section{A. Muravyeva}

Summary. The article is devoted to the analysis of state support for innovative activities. Based on the consideration of the methods of state support for innovation in Russia and abroad, a conclusion is drawn about the situation of innovation policy in the country as a whole.

Keywords: innovation, state support, innovation activities, innovation policy, regulatory framework.
B современной России инновационная деятельность стала развиваться все больше и больше, так как инновации сейчас воздействуют практически на все стороны жизни общества и государства. Именно инновации становятся неким катализатором экономического роста не только страны, но и ее регионов. Вследствие этого повышается конкурентоспособность страны на мировом рынке.

Инновационная деятельность - это функционирование компаний с целью поиска и осуществления инноваций для оптимизации ассортимента и производства товаров и услуг высокого качества, а также модернизации производства [5, с. 72].

Данный вид деятельности представлен в первую очередь определением текущих проблем компании, затем реализацией инновационного процесса и, наконец, организацией данного вида деятельности.

Экономическая политика государства представлена в том числе и инновационной составляющей, в рамках которой само государство осуществляет определение основных задач и направлений деятельности органов государственной власти в научно-технической сфере, как и осуществлении достижений данной области, где в качестве ключевых целей и задач выступают формирование необходимых условий для осуществления инновационной политики, модернизация производственной сферы и формирование надлежащих условий для успешной конкурентоспособности российской продукции на базе внедрения инноваций, а также поддержки данной продукции на международном рынке и улучшения экспортной составляющей [6, с. 108].
Муравьева Александра Олеговна

Московский областной филиал Академии народного хозяйства и государственной службы при Президенте

Российской Федерации 89151589804@mail.ru

Аннотация. Статья посвящена анализу государственной поддержки инновационной деятельности. На основе рассмотрения способов государственной поддержки инновационной деятельности в России и за рубежом сделан вывод о ситуации инновационной политики в стране в целом.

Ключевые слова: инновации, государственная поддержка, инновационная деятельность, инновационная политика, нормативно- правовая база.

Инновационная политика, да и инновационная деятельность в целом требует понимания ее сущности, тенденций и особенностей для эффективного использования этого направления страной как инструмента повышения влияния в мире. Также немало важно отметить тот момент, что инновации развиваются семимильными шагами. И то, что было инновацией вчера, сегодня уже становится устаревшей моделью. В связи с этим возникла и существует до сих пор нужда в постоянной актуализации и совершенствовании способов государственной поддержки инновационных проектов.

Сами способы государственной поддержки инновационных проектов можно разделить на несколько подгрупп:

материальные и нематериальные
прямые и косвенные
федеральные, региональные

К материальным способам государственной поддержки относится финансово-денежная помощь государства какому-то направлению инновационной деятельности или же конкретному инновационному проекту. К нематериальным способам государственной поддержки инновационной деятельности можно отнести законодательное регулирование и обеспечение, социальную политику государства, касательно инновационной деятельности и др.

Прямые методы представлены в первую очередь участием выдающихся ученых в очень значимых мероприятиях на государственном уровне с получением соответствующих почетных званий и наград, что, в сущности, представляет собой существенную моральную под- 
держку. Также сюда к данным мерам поддержки можно отнести инвестирование со стороны государства.

В свою очередь косвенные меры представлены главным образом налоговыми льготами, осуществление которых производится посредством снижения налогооблагаемой базы и налоговых ставок.

В первом случае всевозможные инновационные затраты относятся на издержки производства.

Во втором же случае существуют всевозможные льготы по уплате налога на прибыль, среди которых в нашей стране главной выступает в снижении облагаемой прибыли на сумму средств, направленных на техническое перевооружение, реконструкцию, расширение, обновление производства.

Налогооблагаемая прибыль уменьшается также на сумму средств, направленных на проведение собственных НИР и ОКР, а также в РФФИ и РФТР, но не более $10 \%$ облагаемой прибыли в общей сложности. Налогооблагаемая прибыль уменьшается на сумму дивидендов, выплачиваемых предприятиями физическим лицам, в случае их инвестирования внутри предприятия на техническое перевооружение, реконструкцию и расширение производства, включая затраты на НИР и ОКР [7].

Стимулирование нововведений производится различными методами и способами. В РФ от НДС освобождаются: бюджетные НИР и ОКР; патентно-лицензионные промышленные операции; поступающее в нашу страну научно-техническое оборудование; поступающая в нашу страну продукция на основе договоров с зарубежными предприятиями для одновременных работ в научной сфере; обороты по продажам культурной и научной книжной продукции, а также вся деятельность, которая связана с издательством такой продукции $[4$, с. 186].

Главным образом предназначение льгот по налогу на имущество направлено на то чтобы поддерживать производственные и научные хозяйствующие субъекты.

В нашей стране не облагается налогом имущество научно-исследовательских учреждений, различных учреждений РАН, РАCН, РАMН, РАО, Государственный научный центр и прочие учреждения. Точно таким же предназначением обладают и льготы по уплате земельного налога.

Новейшие технологии в области инноваций являются доступными благодаря поддержке со стороны государства финансового лизинга посредством предоставления различных льгот по данному виду деятельности и соответствующим платежам.
Способы государственной поддержки инновационной деятельности в Российской Федерации делятся на федеральные и региональные в зависимости от источника поддержки конкретного направления.

Улучшение и эффективное развитие экономики возможно благодаря инновационной деятельности, поскольку происходит поэтапная смена отраслей с привычных существующих на те отрасли, в которых осуществляется использование самых передовых технологий, что как раз на сегодняшний день и подтверждается мировой практикой, где примером может служить Германия, в которой практически 100\% прироста ВВП производится посредством использования результатов научно-технической деятельности и инноваций.

Таким образом, инновационная деятельность способствует не только стремительному экономическому и промышленному развитию, но развитием на международном рынке. В развитых западных странах, как правило, научно-технический прогресс и современные инновации, как и модернизация производственной сферы, главным образом и определяют общее эффективное экономическое развитие и потенциал.

В настоящий момент только результативная и надлежащая инновационная политика может с уверенностью определять эффективное развитие экономики, что является стратегическим условием для каждого государства $[4$, c. 186].

Тем не менее, модернизация и внедрение передовых технологий осуществлялось в разных странах по-разному.

К примеру, огромное количество американских учреждений научной сферы проводят свои исследования на контрактной основе и посредством грантов негосударственными учреждениями, т.е. они выступают в качестве основного аспекта в системе НИОКР.

То же самое происходило и в Германии, однако впоследствии стали создаваться сети региональных инновационных фондов с постепенным перенесением центра тяжести инновационной деятельности на малые и средние предприятия.

Большинство азиатских стран, включая также Японию отдали предпочтение самым новейшим и передовым технологиям, потратив на их приобретение громадные средства, когда оставалось лишь после таких затрат доработать некоторые из приобретенных технологий и запустить их в производственную сферу с последующей возможностью рыночной реализации, при этом наибольшую перспективу в данном случае имеют именно малые и средние инновационные предприятия. 
В западноевропейских странах государство поддерживает инновационную деятельность в первую очередь посредством ее стимулирования, совершенствования законодательства в антимонопольной области, как и информационных услуг, а также системы охраны интеллектуальной собственности.

Финансовая поддержка инновационной деятельности в вышеуказанных европейских странах главным образом представлена именно косвенным финансированием.

Здесь же главные научные направления поддерживаются на государственном уровне, однако в данном случае на условиях именно прямого финансирования, а не косвенного.

Очень известна в европейских странах кластерная философия, то есть направленность государственной поддержки инновационной сферы в научных целях и формировании новейших кооперационных связей между организациями и вузами, которые до настоящего момента не сотрудничали между собой.

Также следует отметить, что в европейских странах на государственном уровне осуществляется эффективное развитие патентного законодательства и его практической реализации.

Исходя из нормативно правовых актов, научных трудов, направленных на изучение как инновационной деятельности и политики, так и инноваций в целом, можно говорить о том, что инновационная политика в Российской Федерации в последние годы была направлена на несколько ключевых аспектов жизнедеятельности общества. К ним можно отнести:

- стимулирование инновационного развития академической среды

- разработка нормативно правовой базы для новых инновационных проектов

- развитие инновационного потенциала предпринимательской среды.

Для стимулирования инновационного развития академической среды были созданы такие программы как:

- Программа фундаментальных научных исследований

- Программа «Глобальное образование»

- Программа выявления талантливых ученых.

Разработка нормативно правовой базы для новых инновационных проектов необходима для легализации их деятельности и определения рамок таких инноваций.

Еще одно немаловажное направление государственной поддержки - развитие инновационного потенциала предпринимательской среды. На данный момент активно развиваются инновационные кластеры, инновационный центр «Сколково» и многое другое.

На сегодняшний день можно говорить о том, что инновационная политика в Российской федерации по большей части направлена на развитие инновационного фундамента для предпринимательской среды, в частности малого и среднего бизнеса. Также государством осуществляется привлечение венчурных инвестиций и развитие инноваций в научной среде.

\section{ЛИТЕРАТУРА}

1. Абрамешин А.Е., Воронина Т.П., Молчанова 0.П., Тихонова Е. А., Шленов Ю. В. Инновационный менеджмент: Учебник для вузов / Под ред. Молчановой 0.П.-М.: Вита-Пресс, 2015.- 272 с.

2. Бобков А.Л., Бобков Л. В. Инновации и повышение конкурентоспособности промышленности России. — 2016.-127 с.

3. Гумерова Г.И. Образовательные инновации // Управление инновационными преобразованиями. — 2016.-131 с.

4. Стерхова С. А. Инновационный продукт // Инструменты маркетинга.— 2016.-186 с.

5. Костенко М. А. Правовые основы инновационной деятельности: Учебное пособие. / Таганрог: ТТИ ЮФУ, 2018. — 72 с.

6. Современные тренды инновационного развития экономики: Коллективная монография/ Я. В. Коженко, А.В. Катаев, Т. М. Катаева, Н. В. Лихолетова, Е. Л. Макарова, Л. В. Шаронина; Под ред. Я. В. Коженко.—Уфа: «ОМЕГА САЙНС», 2016. — 108 с.

7. Жиц Г.И. Инновационный потенциал.—Саратов: Сарат. гос. техн. ун-т, 2017.

8. К Конституция Российской Федерации (принята всенародным голосованием 12 дек. 1993) (с учетом поправок, внесенных Законами РФ о поправках к Конституции РФ от 30.12.2008 № 6-ФКЗ, от 30.12.2008 № 7-ФК3, от 05.02.2014 № 2-ФК3, от 21.07.2014 № 11-ФК3)

9. Федеральный закон от 23.08.1996 № 127-Ф3 (ред. от 26.07.2019) «0 науке и государственной научно-технической политике»

10. Федеральный закон от 25.02.1999 № 39-Ф3 (ред. от 25.12.2018) «06 инвестиционной деятельности в Российской Федерации, осуществляемой в форме капитальных вложений»

○ Муравьева Александра Олеговна ( 89151589804@mail.ru ).

Журнал «Современная наука: актуальные проблемы теории и практики» 